Article

\title{
Effects of EGFR Inhibitor on Helicobacter pylori Induced Gastric Epithelial Pathology in Vivo
}

\author{
Jean E. Crabtree ${ }^{1, *}$, Anthony H.T. Jeremy ${ }^{1}$, Cedric Duval ${ }^{1}$, Michael F. Dixon ${ }^{2}$, Kazuma Danjo ${ }^{1}$, \\ Ian M. Carr ${ }^{1}$, D. Mark Pritchard ${ }^{3}$ and Philip A. Robinson ${ }^{1, \uparrow}$
}

1 Leeds Institute of Molecular Medicine, St. James's University Hospital, Leeds LS9 7TF, UK; E-Mails: Anthony.jeremy@evocutis.com (A.H.T.J.); C.Duval@leeds.ac.uk (C.D.); kaz.danjo@nifty.com (K.D.); I.M.Carr@leeds.ac.uk (I.M.C.)

Department of Pathology, University of Leeds, Leeds LS2 9JT, UK;

E-Mail: mikedixon@blueyonder.co.uk

3 Department of Gastroenterology, Institute of Translational Medicine, University of Liverpool, Liverpool L69 3GA, UK; E-Mail: Mark.Pritchard@liverpool.ac.uk

$\dagger$ Deceased.

* Author to whom correspondence should be addressed; E-Mail: j.crabtree@leeds.ac.uk; Tel.: +44-113-383-4615; Fax: +44-113-343-8703.

Received: 13 August 2013; in revised form: 16 September 2013 / Accepted: 26 September 2013 / Published: 14 October 2013

\begin{abstract}
Helicobacter pylori transactivates the Epidermal Growth Factor Receptor (EGFR) and predisposes to gastric cancer development in humans and animal models. To examine the importance of EGFR signalling to gastric pathology, this study investigated whether treatment of Mongolian gerbils with a selective EGFR tyrosine kinase inhibitor, EKB-569, altered gastric pathology in chronic H. pylori infection. Gerbils were infected with $H$. pylori and six weeks later received either EKB-569-supplemented, or control diet, for 32 weeks prior to sacrifice. EKB-569-treated H. pylori-infected gerbils had no difference in $H$. pylori colonisation or inflammation scores compared to infected animals on control diet, but showed significantly less corpus atrophy, mucous metaplasia and submucosal glandular herniations along with markedly reduced antral and corpus epithelial proliferation to apoptosis ratios. EKB-569-treated infected gerbils had significantly decreased abundance of Cox-2, Adam17 and Egfr gastric transcripts relative to infected animals on control diet. EGFR inhibition by EKB-569 therefore reduced the severity of pre-neoplastic gastric pathology in chronically H. pylori-infected gerbils. EKB-569
\end{abstract}


increased gastric epithelial apoptosis in $H$. pylori-infected gerbils which counteracted some of the consequences of increased gastric epithelial cell proliferation. Similar chemopreventative strategies may be useful in humans who are at high risk of developing H.pylori-induced gastric adenocarcinoma.

Keywords: Helicobacter pylori; EGFR inhibitor; EKB-569; epithelial cell proliferation; apoptosis

\section{Introduction}

Infection with the gastric bacterium Helicobacter pylori is associated with increased risk of developing distal gastric cancer [1,2]. The risk of gastric cancer is greatest in those with non-ulcer dyspepsia, or gastric ulceration, who develop gastric atrophy and intestinal metaplasia with long term $H$. pylori infection [3]. The chronic inflammatory response to $H$. pylori [1,2] and pathogen stimulated epithelial signalling responses $[4,5]$ ) contribute to an increased risk of neoplasia. H. pylori strains with the cag pathogenicity island (cag PAI), a type IV secretory system [6], are associated with both increased inflammation and epithelial cell signalling responses [1,2,4,5].

Marked gastric epithelial hyperplasia with $H$. pylori infection occurs in both humans and rodent models [7-12]. EGFR transactivation has been strongly implicated in epithelial hyperproliferation and cancer [13]. Early studies identified that both cag PAI positive and negative H. pylori strains transactivate the EGFR on gastric epithelial cells [14-16] similarly to bacterial pathogens infecting other sites such as Pseudomonas aeruginosa [17]. H. pylori-stimulated EGFR transactivation is dependent on stimulation of heparin binding-epidermal growth factor (HB-EGF) which requires metalloprotease, EGFR and Mek-1 activities [14]. H. pylori induced cleavage of membrane bound proHB-EGF is mediated by a disintegrin and matrix metalloprotease-17 (ADAM17) [18]. Both gastric ADAM17 [19], and EGFR ligands HB-EGF, amphiregulin and EGF [20-22], are increased in patients with $H$. pylori infection and/or gastric cancer and are likely to contribute to epithelial hyperplasia. Additionally H. pylori upregulates EGFR in cultured gastric epithelial cells [23] and blocks EGFR endocytosis [24].

Whilst many studies have investigated $H$. pylori stimulated EGFR signalling responses in vitro $[4,5,14-16,25,26]$, the importance of $H$. pylori EGFR transactivation in vivo in chronic infection has not been investigated. Mongolian gerbils have been extensively used for investigating H. pylori-induced gastritis $[9,10,27]$ which can result in gastric cancer with longer term infection $[28,29]$. H. pylori infection in gerbils, in contrast to mice, induces severe antral active chronic gastritis, which progresses to pan gastritis with corpus atrophy $[9,10]$. Infection is associated with epithelial hyperproliferation $[9,10]$ and with long term infection apoptosis in epithelial cells, which is initially increased, decreases [10]. As EGFR hyperactivity is considered critical in the initiation and progression of epithelial derived tumours, EGFR tyrosine kinase inhibitors have therapeutic potential as chemopreventative agents for gastrointestinal neoplasia [30]. Whilst the chemotherapeutic effects of EGFR-kinase inhibitors on intestinal neoplasia is established in mice [30], their potential for preventing $H$. pylori-induced hyperproliferative disease is unknown. 
The aims of this study were to investigate the effects of a selective EGFR tyrosine kinase inhibitor, EKB-569 [30] on H. pylori-induced gastric pathology, epithelial hyperproliferative responses and expression of genes in the EGFR triple membrane passing signalling (TMPS) cascade which are essential for EGFR transactivation [31]. Our previous longitudinal studies on pathology, epithelial proliferation and apoptosis in $H$. pylori SS1 strain infected Mongolian gerbils identified a significant progression to corpus atrophy and reduction in gastric epithelial cell apoptosis at 36 weeks post-infection [10]. Corpus atrophy is a recognised pre-cursor condition for gastric cancer [1-3]. Based on these earlier kinetic studies [10], the effects of EKB-569 treatment in H. pylori SS1 strain infected Mongolian gerbils were examined at 38 weeks post-infection to assess the effect of treatment on the development of the pre-neoplastic lesion corpus atrophy and associated changes in epithelial cell apoptosis, proliferation and gene expression.

\section{Results}

\subsection{EKB-569 Effects on H. pylori-Induced Epithelial Responses in Vitro}

Previous in vitro studies using "In Cell Western" analysis identified that EKB-569 significantly inhibited $H$. pylori-stimulated ERK1/2 phosphorylation (pERK1/2) in A-431 cells [16]. Inhibitory effects were not specific to strains with a functional cag PAI. ERK1/2 phosphorylation in A-431 cells was examined as a readout of EGFR signalling rather than phosphorylated EGFR due to cross reactivity of pEGFR antibodies with $H$. pylori [16]. Initial in vitro studies determined whether EKB-569 inhibited SS1-induced pERK1/2 in A431 cells. At 100nm and 1,000nm EKB-569 inhibited circa 70\% SS1-induced pERK1/2 relative to untreated SS1-stimulated cells (Table 1).

Table 1. Inhibition of ERK1/2 phosphorylation induced by H. pylori SS1 strain in A-431 epithelial cells by EKB-569. A-431 cells were co-incubated with $H$. pylori strain SS1 for $180 \mathrm{~min}$ with, or without, 60 min EKB-569 pre-incubation. Unstimulated A-431 cells were similarly pre-incubated with, and without, EKB-569. ERK1/2 phosphorylation in H. pylori stimulated and unstimulated cells was quantified by "In Cell Western" analysis of the 700/800 nm Relative Response (RR) [16]. Values represent net values after subtraction of the effect of EKB-569 on the endogenous ERK1/2 phosphorylation in unstimulated cells. The significance between control H. pylori SS1 and EKB-569 treated groups was analysed by paired $t$-test $(* p<0.05 ; * * p<0.001$, Values are mean \pm SEM of 4 independent experiments.

\begin{tabular}{cccccc}
\hline EKB-569 nM & $\mathbf{0}$ & $\mathbf{1 ~ n M}$ & $\mathbf{1 0} \mathbf{n M}$ & $\mathbf{1 0 0} \mathbf{n M}$ & $\mathbf{1 , 0 0 0} \mathbf{n M}$ \\
\hline \multirow{2}{*}{$700 / 800 \mathrm{~nm} \mathrm{RR}$} & $65 \pm 3$ & $31 \pm 10 *$ & $21 \pm 7 * *$ & $19 \pm 8 * *$ & $20 \pm 5 * *$ \\
& $(100 \%)$ & $(48 \%)$ & $(33 \%)$ & $(29 \%)$ & $(32 \%)$ \\
\hline
\end{tabular}

\subsection{H. pylori Infection of Mongolian Gerbils}

The effects of EKB-569 treatment on gastric pathology and corpus atrophy were examined at 38 weeks post-infection. At 38 weeks post-inoculation all gerbils on control diet $(n=7)$ or EKB-569 diet $(\mathrm{n}=8)$ were $H$. pylori positive by microbial culture. Additionally, all inoculated gerbils on EKB-569 and control diet were classified histologically as $H$. pylori infected. No control gerbils were positive 
for $H$. pylori by histology or microbial culture ( $\mathrm{n}=10$ per group). There was no significant difference in H. pylori antral density in EKB-569 treated gerbils (density grade mean $\pm \mathrm{SEM}=1.38 \pm 0.20$ ) compared to gerbils on control diet $(1.43 \pm 0.26)$, or in the corpus mucosa (control and EKB-569 diet, $1.0 \pm 0.0$ ).

\subsection{Gastric Pathology in EKB-569 Treated and Control H. pylori-Infected Gerbils}

In H. pylori-infected gerbils, chronic and active inflammation and atrophy were evident in the antrum at 38 weeks post-infection, but there was no significant difference in scores between infected gerbils on control diet and EKB-569 diets (data not shown). In the corpus mucosa, chronic and active inflammatory scores in $H$. pylori-infected gerbils did not differ between EKB-569 treated and untreated gerbils (Figure 1A,B). In contrast, corpus atrophy (Figure 1C) and corpus mucous metaplasia (Figure 1D) in H. pylori-infected gerbils was significantly lower $(p<0.05)$ in EKB-569 treated gerbils. Uninfected control gerbils on normal diet and EKB-569 diet had histologically normal antral and corpus mucosa.

Figure 1. Gastric corpus histopathology scores in H. pylori infected Mongolian gerbils fed Epidermal Growth Factor Receptor (EGFR) inhibitor diet or control diet; (A) chronic inflammation scores; (B) active inflammation scores; (C) corpus atrophy scores; (D) mucous metaplasia scores. Open circles gerbils on control diet, closed triangles gerbils on EKB-569 diet, $\mathrm{n}=7-8$ per group. Comparisons between groups were made using stratified Chi squared for trend. Bars represent median scores.

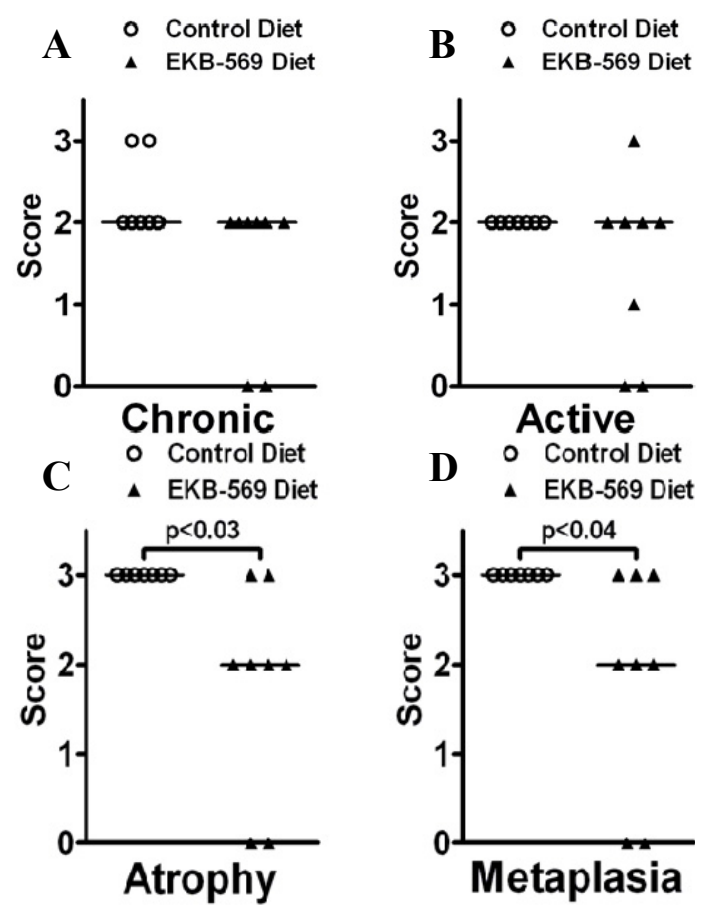

At 38 weeks six of seven $(86 \%) H$. pylori-infected gerbils on control diet had frequent submucosal glandular herniations (Figure 2A). EKB-569 treatment resulted in a significant reduction $(p<0.05$, Fisher's exact test) in glandular herniations which were present in two of eight (25\%) of H. pylori-infected EKB-569 treated gerbils (Figure 2B). Herniation scores were significantly higher ( $p<0.05$, Chi-squared test for trend) in infected gerbils on control diet $(1.57 \pm 0.37)$ than EKB-569 
treated gerbils $(0.50 \pm 0.38)$. Uninfected control gerbils on normal diet and EKB-569 diet had no herniations (Figure 2C,D).

Figure 2. Pathology of gastric mucosa of $H$. pylori infected Mongolian gerbils and uninfected gerbils fed EGFR inhibitor diet or control diet. Haematoxylin and eosin stained sections of gastric antral mucosa of Mongolian gerbils 38 weeks post-infection with H. pylori SS1 strain. (A) H. pylori infected gerbil on control diet, Bar $800 \mu \mathrm{m}$; MM-muscularis mucosa which is discontinuous on the right hand side, three black arrows indicate sub-mucosal glandular herniations. The right hand sub-mucosal herniation is sectioned longitudinally reaching the gastric lumen; (B) Antral mucosa of infected gerbil on EKB-569 diet lacking sub-mucosal herniations, Bar-100 $\mu \mathrm{m}$; (C) Antral mucosa of uninfected gerbil on control diet, Bar-100 $\mu \mathrm{m}$; (D) Corpus mucosa of uninfected gerbil treated with EKB-569, Bar-100 $\mu \mathrm{m}$.
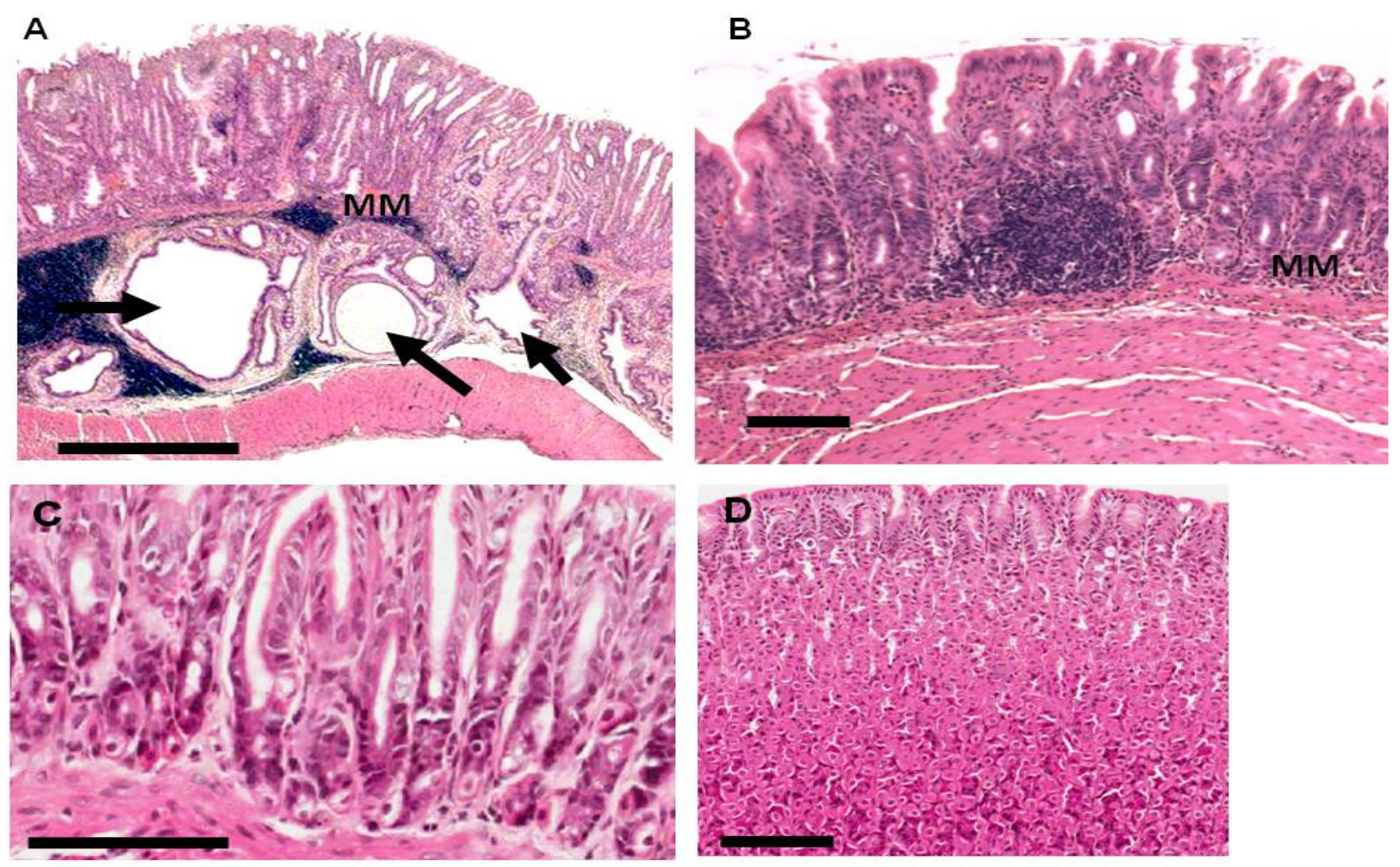

\subsection{EGFR Inhibitor Reduces Phosphorylated Erk Positive Gastric Epithelial Cells in} H. pylori-Infected Gerbils

Immunohistochemistry was used to assess phosphorylation of Erk1/2 in the gastric mucosa in the Mongolian gerbils. At 38 weeks post-infection $H$. pylori infected gerbils on control diet had significantly increased $(p=0.01)$ phosphorylated Erk1/2 gastric epithelial cells relative to the uninfected controls (Figure 3A,B). Both cytoplasmic, and in some instances, nuclear phosphorylated Erk positive epithelial cells were evident mainly in the upper parts of the gastric mucosa in $H$. pylori infected gerbils on the control diet (Figure 3A). However, phospho-Erk positivity was also evident in gastric epithelial cells in the sub-mucosal glandular herniations in infected gerbils on control diet (Figure 3C). Treatment of $H$. pylori infected gerbils with EKB-569 resulted in a significant reduction in phospho-ERK positive epithelial cells compared to H. pylori infected gerbils on control diet (Figure 3D). 
Phospho-Erk1/2 positive mononuclear cells in the lamina propria were evident in $H$. pylori infected gerbils both on the control diet and EKB-569 diet. In uninfected gerbils on control diet and EKB-569 diet there were very few phospho-Erk positive gastric epithelial or lamina propria cells (Figure 3B,E,F). The number of phospho-Erk positive gastric epithelial cells per high-power field $(\times 40)$ in uninfected and H. pylori infected gerbils on control and EKB-569 diet is shown in Figure 3F. The results indicate that EKB-569 significantly reduces $H$. pylori induced gastric phospho-Erk signalling in gastric epithelial cells in vivo $(p<0.002)$ (Figure $3 \mathrm{~F})$ as well as in vitro (Table 1$)$.

\subsection{EGFR Inhibitor Modifies Gastric Epithelial Cell Proliferation Apoptosis Ratios in H. pylori- Infected Gerbils}

In uninfected animals no differences in epithelial proliferation or apoptosis were observed between gerbils on control or EKB-569 diet (Figure 4A-D). At 38 weeks post-infection there was a significant increase in antral $(p<0.001)$ and corpus $(p<0.001)$ epithelial cell proliferation in EKB-569 treated and untreated gerbils compared to uninfected controls (Figures 4A-B). In infected gerbils the corpus epithelial proliferation index in EKB-569 treated gerbils was lower than that of infected gerbils on control diet (Figure 4B). Antral and corpus epithelial apoptosis was significantly increased in H. pylori-infected gerbils treated with EKB-569 compared to H. pylori positive gerbils on control diet $(p<0.01)$ and uninfected control groups $(p<0.001)$ (Figure 4C,D).

The ratio of gastric epithelial cell proliferation to apoptosis in EKB-569 treated control and H. pylori infected gerbils is shown in Figure 3E,F. In uninfected gerbils, EKB-569 treatment had no effect on the proliferation to apoptosis ratio. In H. pylori infected gerbils on control diet there was a significant increase in antral epithelial cell proliferation to apoptosis ratio compared to uninfected controls $(p<0.02)$ and the H. pylori infected group treated with EKB-569 $(p<0.01)$. EKB-569 treated infected gerbils had an antral proliferation to apoptosis ratio comparable to uninfected control groups (Figure 4E). In the corpus the gastric epithelial proliferation to apoptosis ratio was similarly significantly increased in $H$. pylori infected gerbils on control diet relative to uninfected controls $(p<0.01)$ and the H. pylori infected group treated with EKB-569 $(p<0.02)$ (Figure 4F). The EKB-569 treated infected gerbils had a corpus proliferation to apoptosis ratio comparable to uninfected untreated controls, but was greater than the uninfected EKB-569 treated group $(p=0.05)$.

\subsection{Sequence Analysis of Gerbil Transcripts}

To facilitate analysis of the effects of EKB-569 on gastric expression of genes involved in H. pylori induced EGFR transactivation, RT-PCR products produced from transcripts coding for Adam17, Egfr and $H b-E g f$ were analysed by agarose gel electrophoresis, DNA bands were excised and gerbil DNA sequenced. The sequences were aligned with respective rodent and human sequences and showed a high degree of homology (Figure S1). The 213 base pair nucleotide encoding for Mongolian gerbil Adam 17 (EMBL Accession number HF679116) was 95\%, 95\%, 95\% and 94\% identical to mouse, rat, Chinese hamster and human orthologues, respectively (Figure S1A). The 216 base pair nucleotide encoding Mongolian gerbil Egfr (EMBL Accession number HF679117) was 92\%, 91\% and 80\% identical to mouse, rat and human orthologues respectively (Figure S1B). The 200 base pair nucleotide 
encoding Mongolian gerbil $\mathrm{Hb}$-egf (EMBL Accession number HF679118) was 93\%, 93\%, 90\% and $79 \%$ identical to mouse, rat, Chinese hamsters and human orthologues, respectively (Figure S1C).

Figure 3. Immunohistological analysis of phospho-Erk labelling in the gastric mucosa of H. pylori SS1 strain infected, and uninfected, Mongolian gerbils treated with EGFR inhibitor diet or control diet. The brown precipitate is diaminobenzidine staining indicating phospho-Erk 1/2. Sections have been counterstained with haematoxylin. Representative images from sections of gastric antral mucosa of Mongolian gerbils 38 weeks post-infection. (A) H. pylori infected gerbil on control diet showing phospho-Erk positive gastric epithelial cells and lamina propria cells. Magnification $\times 130$; (B) Antral mucosa of uninfected gerbil on control diet. Magnification $\times 140$; (C) Antral mucosa of $H$. pylori infected gerbil on control diet showing two large submucosal herniations with phospho-Erk positive epithelial cells (black arrows). Magnification, $\times 120$. MM-muscularis mucosa; (D) Antral mucosa of $H$. pylori infected gerbil treated with EKB-569 diet showing reduced phospho-Erk labelling in gastric epithelial cells. Magnification $\times 140$; (E) Antral mucosa of uninfected gerbil on EKB-569 diet. Magnification $\times 140$; (F) Number of phospho-Erk positive gastric epithelial cells per high-powered field $(\mathrm{n}=5)$ in H. pylori infected $(\mathrm{n}=7$ control diet; $\mathrm{n}=8$ EKB-569 diet) and uninfected Mongolian gerbils ( $\mathrm{n}=4$ control diet; $\mathrm{n}=4$ EKB-569 diet). Data are expressed as mean \pm SEM. Statistical analysis Mann Whitney U test.
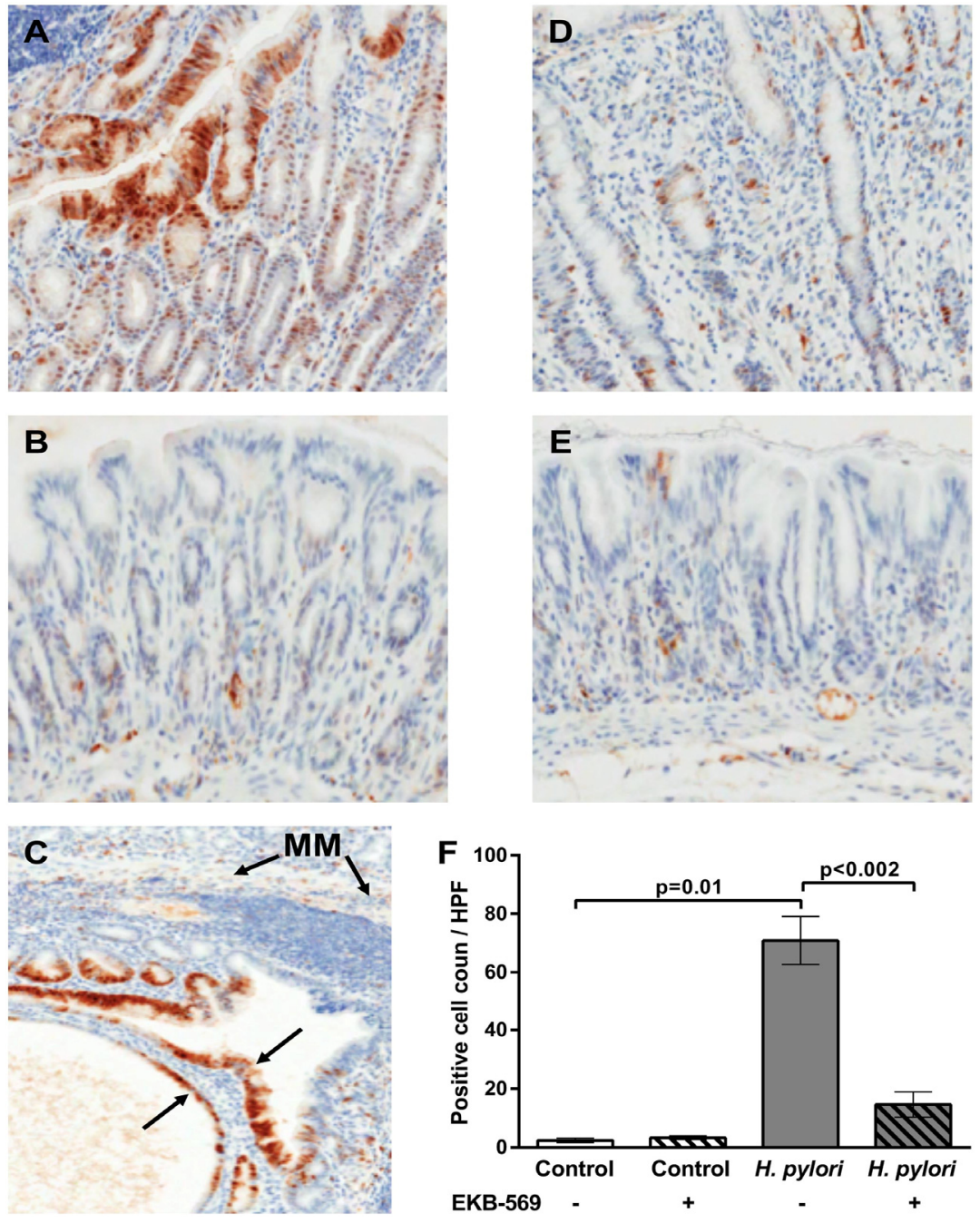
Figure 4. EGFR inhibitor increases apoptosis and decreases gastric epithelial proliferation to apoptosis ratio in $H$. pylori infected gerbils. (A) Epithelial cell proliferation labelling index (LI\%) in the antrum of Mongolian gerbils infected with H. pylori SS1 strain and uninfected controls fed EKB-569 containing diet or control diet; (B) Epithelial cell proliferation labelling index $(\mathrm{LI} \%)$ in the corpus of Mongolian gerbils infected with H. pylori SS1 strain and uninfected controls fed EKB-569 containing diet or control diet; (C) Epithelial cell apoptosis index (AI\%) in the glandular epithelium in the antrum of Mongolian gerbils infected with $H$. pylori SS1 strain and uninfected controls fed EKB-569 containing diet or control diet; (D) Epithelial cell apoptosis index (AI\%) in the glandular epithelium in the corpus of Mongolian gerbils infected with $H$. pylori SS1 strain and uninfected controls fed EKB-569 containing diet or control diet; (E) Proliferation/apoptosis ratio in antrum in infected and control gerbils fed EKB-569 containing diet or control diet; (F) Proliferation/apoptosis ratio in corpus of infected and control gerbils fed EKB-569 containing diet or control diet. Group size $n=7-10$ gerbils. Grey histograms H. pylori infected gerbils on EKB-569 diet and control diet; white bars uninfected gerbils on EKB-569 diet and control diet. Hatched bars infected and control groups treated with EKB-569 diet; unhatched bars infected and control groups on control diet. Data are expressed as mean \pm SEM. Statistical analysis Mann-Whitney U test.

A

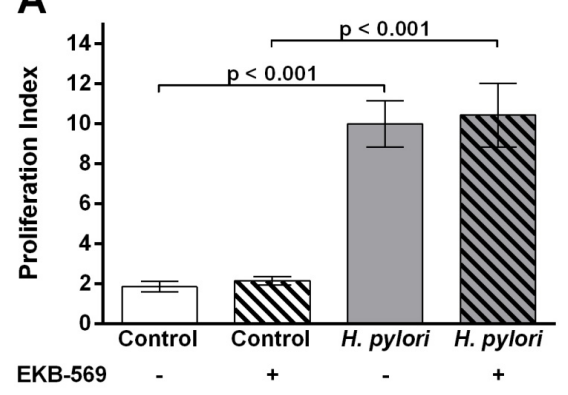

C

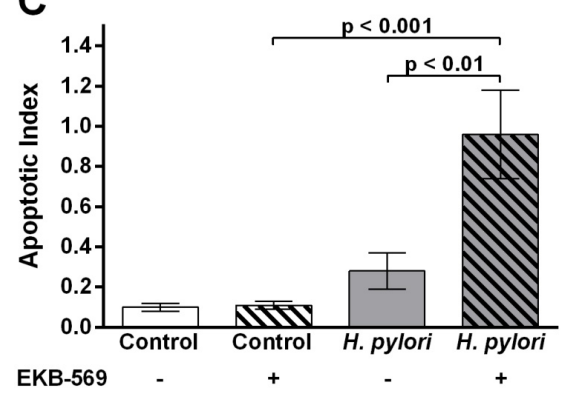

E

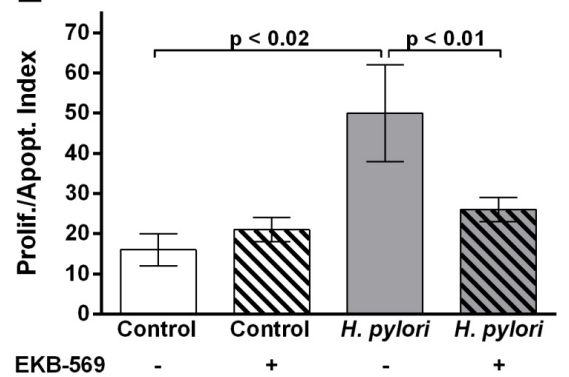

B
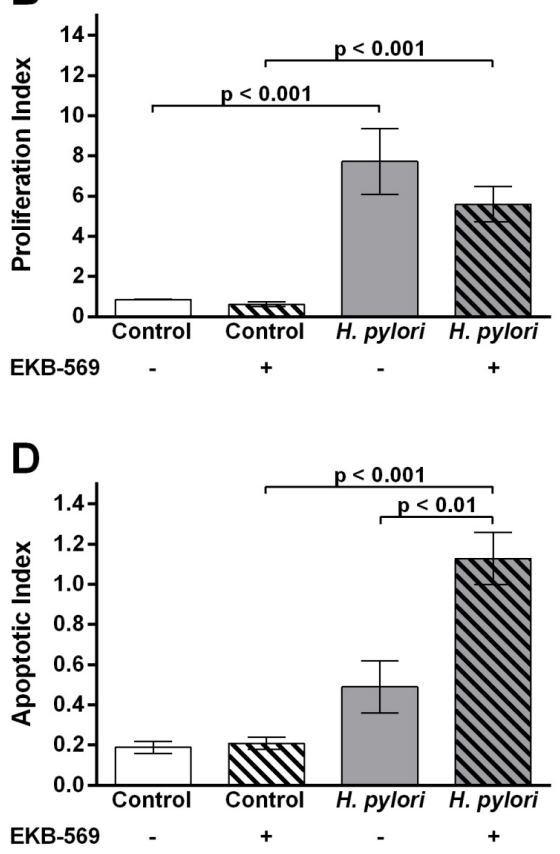

$\mathbf{F}$

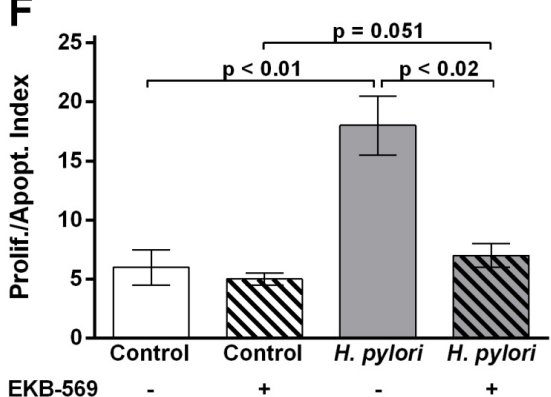




\subsection{Effects of EGFR Inhibitor on H. pylori Induced Gastric Gene Expression in Gerbils}

As $I f n-\gamma$ transcripts in the gastric mucosa of $H$. pylori-infected gerbils have previously been shown to correlate with the grade of chronic inflammation [10], If $n-\gamma$ transcripts were compared in H. pylori-infected EKB-569 treated and untreated gerbils. Transcripts were quantified using the $2^{-\Delta \Delta \mathrm{Ct}}$ method [32] using Gapdh as a reference gene. No significant difference was evident in Ifn- $\gamma$ transcript abundance in H. pylori-infected gerbils on EKB-569 or control diet (data not shown) concurring with their similar chronic inflammatory scores (Figure 1). The miRNAs miR-155 and miR-146a are increased in human gastric mucosa in $H$. pylori infection [33,34]. miRNAs were quantified using the $2^{-\Delta \Delta \mathrm{Ct}}$ method [32] using U6 snRNA as a reference gene. Quantitative PCR showed transcript abundances of miR-146a and miR-155 were also significantly increased $(p<0.01)$ in $H$. pylori SS1-infected gerbils compared to uninfected controls (Figure 5A,B). There was no significant difference in gastric $m i R-146 a$ and $m i R-155$ transcript abundance in infected gerbils on EKB-569 or control diet.

Figure 5. H. pylori infection increases miR-155 and miR-146a abundance in the gastric mucosa which is not modified by EGFR inhibitor treatment. Mongolian gerbils were infected with $H$. pylori SS1 strain for 38 weeks. Real-time PCR was used to quantify the gastric mucosal transcript abundance of (A) miR155 and (B) miR146 in H. pylori infected and control gerbils. Grey histograms, H. pylori infected gerbils; white histograms uninfected control gerbils; Hatched bars infected and control groups treated with EKB-569 diet, unhatched bars infected and control groups on control diet. Group size $n=7-10$ gerbils. Results are expressed as mean \pm SEM. ** $p<0.01$ Mann-Whitney Test.
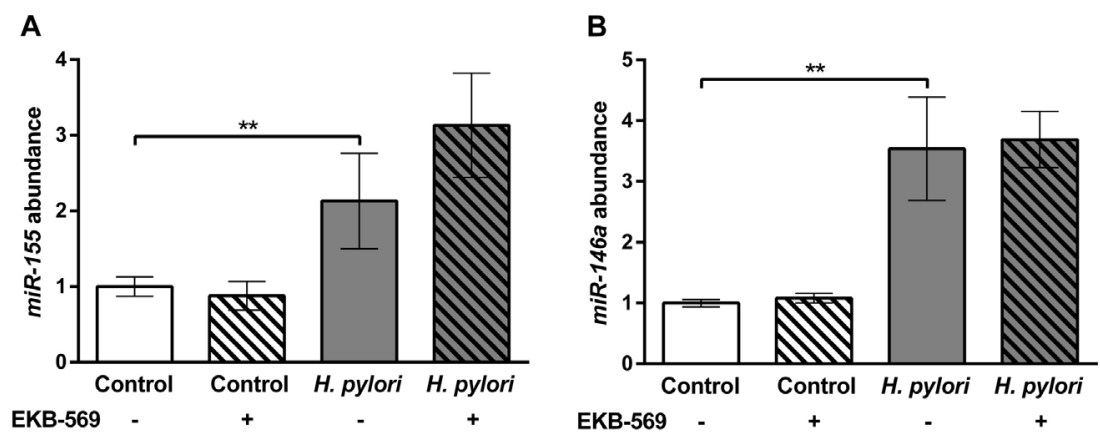

Analysis of Adam-17, Egfr and Cox-2 in the gastric mucosa of uninfected control gerbils showed that EKB-569 had no significant effect on transcript abundance of these genes (Figure 6A-C). In contrast H. pylori infection resulted in significant increases in gastric mucosal Adam17 $(p<0.01), E g f r$ $(p<0.05)$ and Cox-2 $(p<0.01)$ transcript abundance in gerbils on control diet (Figure 6A-C). EKB-569 treatment of $H$. pylori-infected gerbils significantly reduced the abundance of Adam17 $(p<0.01), \operatorname{Cox}-2$ $(p<0.01)$ and decreased Egfr gastric mucosal transcripts (Figure 5A-C). HB-EGF expression is upregulated in cultured human gastric epithelial cells by $H$. pylori $[14,35]$ and HB-EGF is also present in parietal cells [36]. EKB-569 treatment of uninfected gerbils resulted in increased $H b$-egf transcripts $(p<0.05)$ (Figure 6D). No increase in Hb-egf transcripts was observed in H. pylori-infected gerbils on control diet relative to uninfected controls on control diet. However in H. pylori-infected gerbils a significant decrease $(p<0.01)$ was evident in animals treated with EKB-569 (Figure 6D). 
Figure 6. EGFR inhibitor treatment decreases H. pylori induced Adam 17, Egfr and Cox2 transcript abundance in gastric mucosa. Gerbils were infected with $H$. pylori SS1 strain for 38 weeks. Real-time PCR was used to quantify the gastric mucosal transcript abundance of (A) Adam 17; (B) Egfr; (C) Cox-2; (D) Hb-egf in H. pylori infected gerbils and controls. Grey histograms H. pylori infected gerbils, white histograms uninfected control gerbils; Hatched bars infected and control groups treated with EKB-569 diet, unhatched bars infected and control groups on control diet. Group size $n=7-10$ gerbils. Results are expressed as mean \pm SEM. ${ }^{*} p<0.05 ; * * p<0.01$ Mann-Whitney Test.
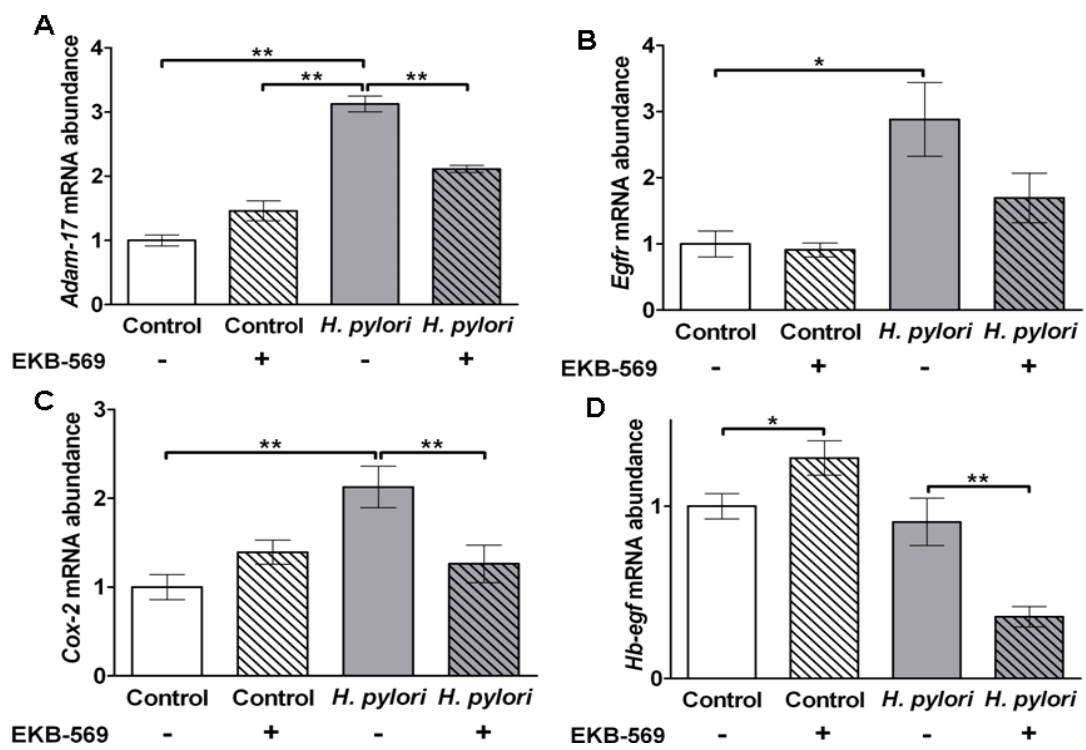

\section{Discussion}

H. pylori can directly transactivate the EGFR on epithelial cells [14-16] and peptides such as gastrin [37], chemokines [38] and molecules such as $\mathrm{PGE}_{2}$ [39] which are upregulated by H. pylori will also, via their specific $\mathrm{G}$ coupled protein receptors, induce EGFR transactivation. Thus, in vivo, multiple pathways induced by H. pylori may contribute to EGFR transactivation via the TMPS cascade, which involves extracellular cleavage of membrane bound EGFR ligands such as proHB-EGF and amphiregulin by ADAM metalloproteases [4].

EKB-569 is a potent selective irreversible inhibitor of EGFR tyrosine kinase activity both in vitro and in vivo in rodents at clinically relevant doses [30,40]. EKB-569 also has reduced activity against ErbB-2 (HER2/neu) [30] which is also activated by H. pylori [41]. EKB-569 administration in dietary formulation blocks intestinal polyp formation in $\mathrm{APC}^{\mathrm{Min} /+}$ mice [30] and combination therapy with cyclooxygenase inhibitors results in synergistic prevention of polyp development [30]. This latter study only investigated polyp formation and did not evaluate any effects of EKB-569 on epithelial kinetics and intestinal gene expression.

In the present study EKB-569 significantly reduced H. pylori phosphorylation of ERK1/2 in gastric epithelial cells both in vitro and in vivo. In addition, nuclear phospho-Erk was mainly observed in H. pylori infected gerbils on control diet. Previous studies indicate nuclear accumulation of Erk2 depends on phosphorylation state and dimerization [42]. Phospho-Erk positive mononulcear cells in the lamina propria were present in infected gerbils on both control diet and EKB-569 diet. Although 
EGFR is strongly expressed on the basal lateral membranes of gastrointestinal epithelial cells [43], EGFR is also present in myeloid cells [44] and fibroblasts [45] which are increased in H. pylori infection [46]. The lack of specific reagents for gerbils precluded detailed analysis of the lamina propria specific mononuclear cell populations. The potential effects of EKB-569 on the function of lamina propria mononuclear cell populations should be considered in future studies given the importance of epithelial-stromal interactions in disease pathogenesis [46].

In the present study in vivo EKB-569 treatment of gerbils during weeks 6 to 38 post-infection had no effect on density of $H$. pylori colonisation or gastric inflammation determined histologically and by assessment of gastric If $n \gamma$, miR-146a and miR-155 transcripts, respectively. Gastric miR-146a and miR-155 transcripts, which were significantly increased in $H$. pylori infected gerbils on both EKB-569 and control diets, negatively regulate the inflammatory response to $H$. pylori $[33,34]$. In contrast, in H. pylori infected gerbils, EKB-569 treatment was associated with significantly reduced corpus atrophy (the pre-neoplastic lesion end point), mucous metaplasia and glandular submucosal herniations and a marked reduction in antral and corpus epithelial to apoptosis ratios. Consistent with previous studies with $H$. pylori SS1 strain [10], no gerbils in this study had dysplasia or cancer.

EKB-569 treatment of infected gerbils significantly increased gastric epithelial apoptosis relative to infected gerbils on control diet at 38 weeks post-infection. Enhanced gastric epithelial cell apoptosis and the reduced proliferation to apoptosis ratio may account for the significant reduction in submucosal herniations, the latter being a proliferative response considered to be a first-step in the development of adenocarcinoma in this model. Whether enhanced apoptosis contributes to the significant reduction in corpus atrophy and a diminished requirement for mucous metaplasia requires further investigation. Earlier studies on murine airway epithelium have shown EKB-569 interrupts viral induced anti-apoptotic pathways and partially inhibits goblet cell metaplasia [47]. Previous studies have shown a significant reduction in gastric epithelial cell apoptosis in gerbils at 38 weeks post-infection with $H$. pylori SS1 strain relative to 12 weeks post-infection [10]. The $H$. pylori CagA protein can inhibit vacuolating cytotoxin induced apoptosis in epithelial cell lines [48]. However as the SS1 strain does not have a functional cag PAI [49], epithelial CagA translocation is unlikely to be involved in the decline in epithelial apoptosis in untreated infected gerbils.

The increased gastric epithelial apoptosis in EKB-569 treated infected gerbils was associated with a significant decrease in Cox-2, Adam17 and Egfr gastric transcripts. Gastric cyclooxygenase-2 is increased in $H$. pylori infection [50] and elevated levels of $\mathrm{PGE}_{2}$ will transactivate the EGFR [39] decreasing apoptosis. Reduction of Cox-2 gastric transcripts in EKB-569 treated gerbils is in line with previous studies showing that upregulation of COX-2 protein in human [51] and murine [52] gastric epithelial cell lines by $H$. pylori is dependent on EGFR transactivation. Furthermore, pharmacological inhibition of Cox-2 upregulation in H. pylori stimulated murine gastric epithelial cells increases apoptosis [52]. Clinically in $H$. pylori infected patients with gastric ulcers the use of non-steroidal anti-inflammatory drugs reduces the risk of gastric cancer [53]. The synergistic effects of cycloxygenase inhibitors and EKB-569 on polyp formation in $\mathrm{APC}^{\mathrm{Min} /+}$ mice [30] may similarly result from increased apoptosis.

Surprisingly no significant increase in gastric $H b-e g f$ transcripts was observed in untreated gerbils with $H$. pylori infection relative to uninfected controls, although a significant reduction of $H b-e g f$ transcript abundance was evident in infected gerbils with EKB-569 treatment. Although antral mucosa 
was used to avoid $H b$-egf positive parietal cells [36], possible parietal cells in the transition zone in two control gerbils with high $H b$-egf transcripts may have precluded the expected increase in $H b$-egf transcripts with $H$. pylori infection. In vitro studies with human MKN-28 gastric cancer cells have shown H. pylori induced upregulation of $C O X-2$ and $H B-E G F$, but not $A D A M 17$, is reduced by EKB-569 treatment [54]. EGF stimulated upregulation of $C O X-2$ and $H B-E G F$, but not $A D A M 17$, in human MKN-28 gastric epithelial cells are also downregulated by EKB-569 treatment [54].

The membrane metalloprotease ADAM17 has a critical role in cleaving proHB-EGF on gastric epithelial cells following $H$. pylori stimulation resulting in EGFR transactivation by mature HB-EGF [14,18]. In vitro studies indicate that ADAM17 is required for the anti-apoptotic effect of H. pylori [18]. The significant decrease in Egfr transcripts in the gastric mucosa of infected gerbils with EKB-569 treatment probably reflects an overall reduction in gastric epithelial cells. These in vivo observations in gerbils concur with previous studies in an immortalised gastric epithelial cell line in which EGFR knockdown by siRNA enhanced $H$. pylori stimulated apoptosis [18].

In gastric cancer the expression of $A D A M 10, A D A M 15, A D A M 17$ and $A D A M 20$ transcripts is markedly increased [19]. In addition, increases in EGF-related peptides HB-EGF and amphiregulin are evident in patients with $H$. pylori infection and/or gastric cancer [20,22]. Upregulation of these key components for EGFR transactivation by $H$. pylori could promote autocrine signaling loops promoting epithelial hyperproliferation and block apoptosis.

Although no significant reduction in gastric epithelial proliferation was identified with EKB-569 treatment in infected gerbils, in vivo rodent studies with other carcinogens such as asbestos, which also transactivates the EGFR [55], indicate bronchial hyperproliferative responses are dependent on EGFR activation [56]. Asbestos induced inflammation alone in transgenic mice with mutant EGFR was not associated with epithelial hyperproliferative responses nor proto-oncogene activation [56]. In $\mathrm{H}$. pylori SS1-infected gerbils gastric epithelial proliferation, but not apoptosis, correlates with active and chronic inflammatory scores [10]. The lack of reduction in epithelial cell proliferation with EKB-569 treatment in the present study is thus consistent with absence of changes in gastric inflammation in this model. Studies in immune deficient transgenic mice also indicate the important role of gastric inflammation in development of epithelial hyperproliferative responses to gastric Helicobacter infection [57]. The lack of effect of EKB-569 on antral epithelial proliferation in infected gerbils suggests multiple pathways may contribute to the epithelial hyperproliferative response.

\section{Experimental}

\subsection{H. pylori Culture}

H. pylori SS1 strain was grown on blood agar base with 7\% (v/v) horse blood under microaerobic conditions at $37{ }^{\circ} \mathrm{C}$. For in vitro experiments two day cultures were harvested into antibiotic-free RPMI 1640 medium and suspended at a concentration of $2.5 \times 10^{7}$ organisms $/ \mathrm{mL}$. For in vivo experiments two day SS1 cultures were harvested into sterile tryptose soya broth and used immediately for inoculation into gerbils. 


\subsection{In Vitro Bacterial-Epithelial Co-Culture}

A-431 (ATCC CRL-1555) (American Type Culture Collection, Manassas, VA, USA) human epidermoid carcinoma cells, which express high levels of EFGR, were used. To examine the effects of EKB-569 on H. pylori SS1-stimulated ERK1/2 activation over night serum starved A-431 in 96 well plates (Nunc, Rochester, NY, USA)were pre-incubated with EKB-569 at concentrations of 0, 0.01, 0.1, 0.5, $1.0 \mu \mathrm{M} /$ well for $1 \mathrm{hr}$ prior to co-culture with $H$. pylori $\mathrm{SS} 1$ for $3 \mathrm{~h}$ as previously described [16]. EKB-569 was kindly provided by L. Greenberger (Wyeth Research Chemical Sciences, Pearl River, NY, USA). Inhibition of $H$. pylori-stimulated ERK1/2 phosphorylation was quantified by "In Cell Western" assay using mouse mouse-monoclonal anti-pERK1/2 (Santa Cruz, Dallas, TX, USA) and rabbit-polyclonal anti-ERK1 (Santa Cruz) antibodies as previously described [16]. The $700 \mathrm{~nm}$ Relative Value (Rel $\left.{ }_{700}\right)$ was obtained after normalization with $800 \mathrm{~nm}$ values to control for cell density variation [16].

\subsection{Infection of Mongolian Gerbils with H. pylori}

Male Mongolian gerbils aged 6-8 weeks old (supplied by MGS/Sea, Seac Yoshimoto, Fukuoka, Japan and bred at the University of Leeds) were inoculated three times by oral gavage with $H$. pylori SS1 ( $\left.>10^{8} \mathrm{CFU}\right)$ over a 5 day period. Inoculated and control gerbils were maintained under a $12 \mathrm{~h}$ light/dark cycle, temperature $19-23{ }^{\circ} \mathrm{C}$ and humidity $45 \%-55 \%$. After six weeks inoculated and control animals $(\mathrm{n}=8-10)$ received per os $10 \mathrm{mgs} / \mathrm{kg} /$ day/gerbil EKB-569 in dietary formulation or control. Previous rodent studies [30] have demonstrated the efficacy of this dose in long term inhibition of EGFR activity. All experimental procedures were approved by the local ethics committee of Leeds University and the UK Home Office.

\subsection{Histological and Microbial Analysis of H. pylori Infection}

Gerbils were sacrificed at 38 weeks post-inoculation. One hour prior to sacrifice inoculated gerbils and controls received an intra-peritoneal injection of bromodeoxyuridine (BrdU) (50 mg/kg). At sacrifice, gastric tissue was taken for microbial culture, histology and snap frozen in liquid nitrogen and stored at $--70{ }^{\circ} \mathrm{C}$ for subsequent RNA extraction. H. pylori culture from gastric mucosa was on selective plates as previously described [12].

Gastric pathology was graded on haematoxylin and eosin stained sections by a pathologist in a blinded fashion as previously described [10,12]. The entire field of four sections of gastric mucosa was evaluated histologically to give one score for antral and one score for corpus mucosa per gerbil. Gerbils were scored for active and chronic inflammation, atrophy, and mucous metaplasia. All parameters were graded on a scale of $0-3$, with 0 being histologically normal, 1 - mild, 2- moderate and 3- severe abnormality. In addition, the extent of herniations below the muscularis mucosa was scored on a scale $0-3$, with a score of zero being no herniations, 1- mild, 2- moderate and 3 severe submucosal herniations. Density of H. pylori in antrum and corpus was assessed on Giemsa stained sections as previously described [10]. Gastric epithelial cell proliferation was assessed by BrdU immunohistochemistry as previously described [10-12]. Epithelial cell proliferation was expressed as a labelling index $(\mathrm{LI} \%)$ ([percentage of stained cells/total cells per gastric gland] $\times 100)$. 
Apoptotic epithelial cells were identified immunohistochemically with a rabbit polyclonal antibody against active caspase 3 (Cell Signalling Technology, Danvers, MA, USA). Glandular epithelial apoptosis was expressed as an apoptotic index (AI\%) ([percentage of stained cells /total cells per gastric gland] $\times 100$ ) as previously described $[10,11]$. Quantitative assessments were undertaken on a Nikon E1000 microscope (Nikon Inc., Melville, NY, USA). To evaluate changes in epithelial cell proliferation and apoptosis, a score for epithelial cell kinetics in individual gerbils was determined by dividing the epithelial proliferation index (LI\%) by the apoptotic index (AI\%) [7].

Immunohistological analysis of phospho-p44/p42 Map Kinase (Erk 1/2) (Thr202/Tyr204) activation in the gastric epithelium was undertaken using a rabbit monoclonal antibody (4370) (Cell Signaling Technology) and EnVision+Dual System-HRP (DAB+) (Dako, Carpinteria, CA, USA). The number of phospho-Erk positive gastric epithelial cells per high-power field was determined as previously described [58].

\subsection{Sequence Analysis of Mongolian Gerbil Genes}

Primers specific for $A d a m 17, E g f r$ and $H b-E g f$ transcripts were designed by cross species PCR after aligning respective murine, rat and human sequences and identifying regions of homology. PCR products were sequenced as previously described [27].

\subsection{Quantitative Polymerase Chain Reaction ( $q P C R$ )}

Gastric mucosal RNA was extracted in Trizol (Invitrogen, Paisley, UK), DNase treated (Applied Biosystems, Warrington, UK) and reverse-transcribed with SuperScript II Reverse Transcriptase (Invitrogen, Paisley, UK) and random hexamers (Bioline, London, UK). Real-time qPCR amplification was performed using gene-specific oligonucleotide primers for Adam17, Cox-2, Egfr, Hb-egf, Ifn- $\gamma$, and Gapdh (Table 2) and SYBR Green PCR Master Mix (Applied Biosystems). Quantitative PCR amplification consisted of an initial denaturing step at $95{ }^{\circ} \mathrm{C}$ for $10 \mathrm{~min}, 40$ cycles of $95{ }^{\circ} \mathrm{C}$ for $15 \mathrm{~s}$ and $60{ }^{\circ} \mathrm{C}$ for $1 \mathrm{~min}$. Reactions were performed in a 7500 Real Time PCR System (Applied Biosystems) and quantified using $2^{-\Delta \Delta \mathrm{Ct}}$ method [32] using Gapdh as a reference gene.

Table 2. Primers used for quantitative real-time polymerase chain reaction (q-PCR).

\begin{tabular}{|c|c|c|}
\hline Gene & Primers & Product size (bp) \\
\hline Adam 17 & $\begin{array}{c}\text { 5'-AAAGGGAACCCTGTACCGTAGGG } \\
\text { 5'-GCCAAAAACTTTCCGAAAGTGT }\end{array}$ & 131 \\
\hline Cox-2 & $\begin{array}{l}\text { 5'-AGTCTCTCAACGAATACCGCAAAC } \\
\text { 5'-ATGTCACTGTAGAGGGCTTTCAAC }\end{array}$ & 117 \\
\hline$E g f r$ & $\begin{array}{c}\text { 5'-GGGAAATGCTCTGTACGAAAACAC } \\
\text { 5'-AGCACCGGTCAGGATTTCCT }\end{array}$ & 118 \\
\hline Gapdh & $\begin{array}{c}\text { 5'-CCTGTGACTTTAACAGCGACTCC } \\
\text { 5'-CCATGAGGTCCACCACCCT }\end{array}$ & 102 \\
\hline$H b-e g f$ & $\begin{array}{c}\text { 5'-TCGGAGAGGTCTGGCGG } \\
\text { 5'-TCCTGGACTTCCTGAGTGCG }\end{array}$ & 118 \\
\hline$I f n-\gamma$ & $\begin{array}{l}\text { 5'-CCATGAACGCTACACACTGCATC } \\
\text { 5'-GAAGTAGAAAGAGACAATCTGG }\end{array}$ & 230 \\
\hline
\end{tabular}




\begin{tabular}{ccc} 
miRNAs & Forward Primers & \\
U6 $\boldsymbol{s} \boldsymbol{n} \boldsymbol{R} \boldsymbol{A}$ & 5'-dTGGCCCCTGCGCAAGGATG & - \\
$\boldsymbol{m i \boldsymbol { R } - 1 4 6 \boldsymbol { a }}$ & 5'-dTGAGAACTGAATTCCATGGGTT & - \\
$\boldsymbol{m i \boldsymbol { R } - 1 5 5}$ & 5'-dTTAATGCTAATTGTGATAGGGGT & - \\
\hline
\end{tabular}

\subsection{Quantitative PCR Analysis of miRNAs Expression in Gerbil Gastric Mucosa}

miRNAs were reverse-transcribed from extracted gastric RNA using the miRNome microRNA Profilers QuantiMirTM kit (System Biosciences; Mountain View, CA, USA) following the manufacturer's instructions. Quantitative PCR for miR-146a and miR-155 was performed by real-time PCR, using U6 snRNA as reference gene using forward primers detailed in Table 2 and the 3' universal reverse primer (System Biosciences). Quantitative PCR was as above. miRNAs were quantified using the $2^{-\Delta \Delta \mathrm{Ct}}$ method [32] using U6 snRNA as a reference gene.

\subsection{Statistics}

Results are presented as means \pm S.E.M. Comparisons between groups were made using either Mann-Whitney U test, paired $t$ test, stratified Chi squared for trend or Fishers exact test. A $p$ value of less than $<0.05$ was considered significant.

\section{Conclusions}

In conclusion, this study demonstrates that treatment of $H$. pylori infected gerbils with a selective EGFR inhibitor improves gastric corpus pathology and precancerous lesions and substantially decreases both the antral and corpus epithelial to apoptosis ratios to those of uninfected gerbils. A significant increase in apoptosis in infected gerbils treated with the EFGR inhibitor was associated with reduced mucosal transcripts of Cox-2, Adam 17 and Egfr. These studies indicate for the first time a pathogenic role of $H$. pylori EGFR transactivation in vivo during long term chronic $H$. pylori infection. Targeting pre-malignant proliferative signalling pathways in non-malignant conditions with tyrosine kinase inhibitors is considered to have therapeutic potential for some conditions [59]. Whether such an approach with EGFR inhibitors would have a chemopreventative role in subjects who are at high risk of developing gastric cancer, who have failed $H$. pylori eradication therapy, requires consideration.

\section{Acknowledgments}

The study was undertaken with financial support of Yorkshire Cancer Research and funding under the Sixth Research Framework Programme of the European Union, Project INCA (LSHC-CT-2005-018704).

\section{Conflicts of Interest}

None of the authors have a conflict of interest. EKB-569 was provided by Wyeth Research Chemical Sciences who have had no role in study design, data analysis or preparation of the manuscript. 


\section{References}

1. Peek, R.M.; Crabtree, J.E. Helicobacter infection and gastric neoplasia. J. Pathol. 2006, 208, 233-248.

2. Polk, D.B.; Peek, R.M. Helicobacter pylori: Gastric cancer and beyond. Nat. Rev. Cancer 2012, 10, 403-414.

3. Uemura, N.; Okamoto, S.; Yamamoto, S.; Matsumura, N.; Yamaguchi, S.; Yamakido, M.; Taniyama, K.; Sasaki, N.; Schlemper, R.J. Helicobacter pylori infection and the development of gastric cancer. N. Engl. J. Med. 2001, 345, 784-789.

4. Crabtree, J.E.; Naumann, M. Epithelial cell signalling in Helicobacter pylori infection. Curr. Signal Transduct. Ther. 2006, 1, 53-65.

5. Backert, S.; Naumann, M. What a disorder: Proinflammatory signalling pathways induced by Helicobacter pylori. Trends Microbiol. 2010, 18, 479-486.

6. Censini, S.; Lange, C.; Xiang, Z.; Crabtree, J.E.; Ghiara, P.; Borodovsky, M.; Rappuoli, R.; Covacci, A. cag, a pathogenicity island of Helicobacter pylori, encodes type I-specific and disease-associated virulence factors. Proc. Natl. Acad. Sci. USA 1996, 93, 14648-14653.

7. Peek, R.M.; Moss, S.F.; Tham, K.T.; Pérez-Pérez, G.I.; Wang, S.; Miller, G.G.; Atherton, J.C.; Holt, P.R.; Blaser, M.J. Helicobacter pylori cagA+ strains and dissociation of gastric epithelial cell proliferation and apoptosis. J. Natl. Cancer Inst. 1997, 89, 863-868.

8. Moss, S.F.; Sordillo, E.M.; Abdalla, A.M.; Makarov, V.; Hanzely, Z.; Perez-Perez, G.I.; Blaser, M.J.; Holt, P.R. Increased gastric epithelial cell apoptosis associated with colonisation with cagA+ H. pylori strains. Cancer Res. 2001, 61, 1406-1411.

9. Peek, R.M.; Wirth, H.P.; Moss, S.F.; Yang, M.; Abdalla, A.M.; Tham, K.T.; Zhang, T.; Tang, L.H.; Modlin, I.M.; Blaser, M.J. Helicobacter pylori alters gastric epithelial cell cycle events and gastrin secretion in Mongolian gerbils. Gastroenterology 2000, 118, 48-59.

10. Crabtree, J.E.; Court, M.; Aboshkiwa, M.A.; Jeremy, A.H.T.; Dixon, M.F.; Robinson, P.A. Gastric mucosal cytokine and epithelial cell responses to Helicobacter pylori infection in Mongolian gerbils. J. Pathol. 2004, 202, 197-207.

11. Court, M.; Robinson, P.A.; Dixon, M.F.; Jeremy, A.H.T.; Crabtree, J.E. The effect of gender on Helicobacter felis mediated gastritis, epithelial cell proliferation and apoptosis in the mouse model. J. Pathol. 2003, 201, 303-311.

12. Court, M.; Robinson, P.A.; Dixon, M.F.; Crabtree, J.E. Gastric Helicobacter infection in murine and gerbil models: comparative analysis of effects of $H$. pylori and $H$. felis on gastric epithelial cell proliferation. J. Infect. Dis. 2002, 186, 1348-1352.

13. Fischer, O.M.; Hart, S.; Gschwind, A.; Ullrich, A. EGFR signal transactivation in cancer cells. Biochem. Soc. Trans. 2003, 31, 1203-1208.

14. Wallasch, C.; Crabtree, J.E.; Bevac, D.; Robinson, P.A.; Wagner, H.; Ullrich, A. Helicobacter pylori stimulated EGF receptor transactivation requires metalloprotease cleavage of HB-EGF. Biochem. Biophys. Res. Commun. 2002, 295, 695-701.

15. Keates, S.; Sougioultzis, S.; Keates, A.C.; Zhao, D.; Peek, R.M.; Shaw, L.M.; Kelly, C.P. cag+ Helicobacter pylori induce transactivation of the epidermal growth factor receptor in AGS gastric epithelial cells. J. Biol. Chem. 2001, 276, 48127-48134. 
16. Du, Y.; Danjo, K.; Robinson, P.A.; Crabtree, J.E. In-Cell Western analysis of Helicobacter pylori induced phosphorylation of extracelluar-signal related kinase via the transactivation of the epidermal growth factor receptor. Microbes Infect. 2007, 9, 838-846.

17. Zhang, J.; Li, H.; Wang, J.; Dong, Z.; Mian, S.; Yu, F.X. Role of EGFR transactivation in preventing apoptosis in Pseudomonas aeruginosa-infected human corneal epithelial cells. Invest. Ophthalmol. Vis. Sci. 2004, 45, 2569-2576.

18. Yan, F.; Cao, H.; Chaturvedi, R.; Krishna, U.; Hobbs, S.S.; Dempsey, P.J.; Peek, R.M., Jr.; Cover, T.L.; Washington, M.K.; Wilson, K.T.; et al. Epidermal growth factor receptor activation protects gastric epithelial cells from Helicobacter pylori-induced apoptosis. Gastroenterology 2009, 136, 1297-1307.

19. Yoshimura, T.; Tomita, T.; Dixon, M.F.; Axon, A.T.R.; Robinson, P.A.; Crabtree, J.E. ADAMs mRNA expression in Helicobacter pylori infected, normal and neoplastic gastric mucosa. J. Infect. Dis. 2002, 185, 332-340.

20. Cox, J.M.; Clayton, C.L.; Tomita, T.; Wallace, D.M.; Robinson, P.A.; Crabtree, J.E. cDNA array analysis of cag pathogenicity island-associated $H$. pylori epithelial cell response genes. Infect. Immun. 2001, 69, 6970-6980.

21. Wong, B.C.; Wang, W.P.; So, W.H.; Shin, V.Y.; Wong, W.M.; Fung, F.M.; Liu, E.S.; Hiu, W.M.; Lam, S.K.; Cho, C.H. Epidermal growth factor and its receptor in chronic active gastritis and gastroduodenal ulcer before and after H. pylori eradication. Aliment. Pharmacol. Ther. 2001, 15, 1459-1465.

22. Naef, M.; Yokoyama, M.; Friess, H.; Buchler, M.W.; Korc, M. Co-expression of heparin-binding EGF-like growth factor and related peptides in human gastric carcinoma. Int. J. Cancer 1996, 66, 315-321.

23. Keates, S.; Keates, A.C.; Katchar, K.; Peek, R.M., Jr.; Kelly, C.P. Helicobacter pylori induces up-regulation of the epidermal growth factor receptor in AGS gastric epithelial cells. J. Infect. Dis. 2007, 196, 95-103.

24. Bauer, B.; Bartfeld, S.; Meyer, T. H. pylori selectively blocks EGFR endocytosis via the non-receptor kinase c-Abl and CagA. Cell. Microbiol. 2009, 11, 156-169.

25. Tabassam, F.; Graham, D.Y.; Yamaoka, Y. Helicobacter pylori activate epidermal growth factor receptor-and phosphatidylinositol 3-OH kinase-dependent Akt and glycogen synthase kinase $3 \beta$. Cell. Microbiol. 2009, 11, 70-82.

26. Tegtmeyer, N.; Zabler, D.; Schmidt, D.; Hartig, R.; Brandt, S.; Backert, S. Importance of EGFR receptor: HER2/Neu and Erk 1/2 kinase signalling for host cell elongation and scattering induced by Helicobacter pylori CagA protein: Antagonistic effects of the vacuoalting cytotoxin VacA. Cell. Microbiol. 2009, 11, 488-505.

27. Wang, J.; Court, M.; Jeremy, A.H.T.; Aboshkiwa, M.A.; Robinson, P.A.; Crabtree, J.E. Infection of Mongolian gerbils with Chinese Helicobacter pylori strains. FEMS Immunol. Med. Microbiol. 2003, 36, 207-213.

28. Watananabe, T.; Tada, M.; Nagai, H.; Sasaki, S.; Nakao, M. Helicobacter pylori infection induces gastric cancer in Mongolian gerbils. Gastroenterology 1998, 115, 642-648. 
29. Franco, A.T.; Israel, D.A.; Washington, M.K.; Krishna, U.; Fox, J.G.; Rogers, A.B.; Neish, A.S.; Collier-Hyams, L.; Perez-Perez, G.I.; Hatakeyama, M.; et al. Activation of $\beta$-catenin by carcinogenic Helicobacter pylori. Proc. Natl. Acad. Sci. USA 2005, 102, 10646-10651.

30. Torrance, C.J.; Jackson, P.E.; Montgomery, E.; Kinzler, K.W.; Vogelstein, B.; Wissner, A.; Nunes, M.; Frost, P.; Discafani, C.M. Combinatorial chemoprevention of intestinal neoplasia. Nat. Med. 2000, 6, 1024-1028.

31. Prenzel, N.; Zwick, E.; Daub, H.; Leserer, M.; Abraham, R.; Wallasch, C.; Ullrich, A. EGF receptor transactivation by G-protein-coupled receptors requires metalloproteinase cleavage of proHB-EGF. Nature 1999, 402, 884-888.

32. Livak, K.J.; Schmittgen, T.D. Analysis of relative gene expression data using real-time quantitative PCR and the 2(-Delta Delta C (T)) method. Methods 2001, 25, 402-408.

33. Xiao, B.; Liu, Z.; Li, B.S.; Tang, B.; Li, W.; Guo, G.; Shi, Y.; Wang, F.; Wu, Y.; Tong, W.D.; et al. Induction of microRNA-155 during Helicobacter pylori infection and it's negative regulatory role in the inflammatory response. J. Infect. Dis. 2009, 200, 916-925.

34. Liu, Z.; Xiao, B.; Tang, B.; Li, B.; Li, N.; Zhu, E.; Guo, G.; Gu, J.; Zhuang, Y.; Liu, X.; et al. Up-regulated microRNA-146a negatively modulate Helicobacter pylori-induced inflammatory response in human gastric epithelial cells. Microbes Infect. 2010, 12, 854-863.

35. Busiello, I.; Acquaviva, R.; di Popolo, A.; Blanchard, T.G.; Ricci, V.; Romano, M.; Zarrilli, R. Helicobacter pylori $\gamma$-glutamyltranspeptidase upregulates Cox-2 and EGF-related peptide expression in human gastric cells. Cell. Microbiol. 2004, 6, 255-267.

36. Beales, I.L.P. Gastrin and interleukin-1 beta stimulate growth factor secretion from cultured rabbit gastric parietal cells. Life Sci. 2004, 75, 2983-2995.

37. Varro, A.; Noble, P.J.; Wroblewski, L.E.; Bishop, L.; Dockray, G.J. Gastrin-cholecystokinin ${ }_{B}$ receptor expression in AGS cells is associated with direct inhibition and indirect stimulation of cell proliferation via paracrine activation of the epidermal growth factor receptor. Gut 2002, 50, 827-833.

38. Tanida, S.; Joh, T.; Itoh, K.; Kataoka, H.; Sasaki, M.; Ohara, H.; Nakazawa, T.; Nomura, T.; Kinugasa, Y.; Ohmoto, H.; et al. The mechanisms of EGFR ligands induced by inflammatory cytokines in gastric cancer cells. Gastroenterology 2004, 127, 559-569.

39. Pai, R.; Soreghan, B.; Szabo, I.L.; Pavelka, M.; Baatar, D.; Tarnawski, A.S. Prostaglandin $E_{2}$ tranactivates EGF receptor: A novel mechanism for promoting colon cancer growth and gastrointestinal hypertrophy. Nat. Med. 2002, 8, 289-293.

40. Wissner, A.; Overbeek, E.; Reich, M.F.; Floyd, M.B.; Johnson, B.D.; Mamuya, N.; Rosfjord, E.C.; Discafani, C.; Davis, R.; Shi, X.; et al. Synthesis and structure activity relationships of 6,7-disubstituted 4-anilinoquinoline-3-carbonitriles. The design of an orally active, irreversible inhibitor of the tyrosine kinase activity of the EGFR and human epidermal growth factor receptor-2 (HER-2). J. Med. Chem. 2002, 46, 49-63.

41. Naumann, M.; Crabtree, J.E. Helicobacter pylori-induced epithelial signalling in gastric carcinogenesis. Trends Microbiol. 2004, 12, 29-36.

42. Khokhlatchev, A.V.; Canagarajah, B.; Wilsbacher, J.; Robinson, M.; Atkinson, M.; Goldsmith, E.; Cobb, M.H. Phosphorylation of the MAP Kinase ERK2 promotes its homodimerization and nuclear translocation. Cell 1998, 93, 605-615. 
43. Playford, R.J.; Hanby, A.M.; Gschmeissner, S.; Peiffer, L.P.; Wright, N.A.; McGarrity, T. The epidermal growth factor receptor (EGF-R) is present on the basolateral, but not the apical, surface of enterocytes in the human gastrointestinal tract. Gut 1996, 39, 262-266.

44. Chan, G.; Nogalski, M.T.; Yurochko, A.D. Activation of EGFR on monocytes is required for human cytomegalovirus entry and mediates cellular motility. Proc. Natl. Acad. Sci. USA 2009, 106, 22369-22374.

45. Kajanne, R.; Miettinen, P.; Mehlem, A.; Leivonen, S.K.; Birrer, M.; Foschi, M.; Kahari, V.M.; Leppa, S. EGF-R regulates MMP function in fibroblasts through MAPK and AP-1 pathways. J. Cell. Physiol. 2007, 212, 489-497.

46. McCaig, C.; Duval, C.; Hemers, E.; Steele, I.; Pritchard, D.M.; Przemeck, S.; Dimaline, R.; Ahmed, S.; Bodger, K.; Kerrigan, D.D.; et al. The role of matrix metalloproteinase-7 in redefining the gastric microenvironment in response to Helicobacter pylori. Gastroenterology 2006, 130, 1754-1763.

47. Tyner, J.W.; Kim, E.Y.; Ide, K.; Pelletier, M.R.; Roswitt, W.T.; Morton, J.D.; Battaile, J.T.; Patel, A.C.; Patterson, G.A.; Castro, M.; et al. Blocking airway mucous cell metaplasia by inhibiting EGFR antiapoptosis and IL-13 transdifferentiation signals. J. Clin. Invest. 2006, 116, 309-321.

48. Oldani, A.; Cormont, M.; Hofman, V.; Chiozzi, V.; Oregioni, O.; Canonici, A.; Sciullo, A.; Sommi, P.; Fabbri, A.; Ricci, V.; et al. Helicobacter pylori counteracts the apoptotic action of its VacA toxin by injecting the CagA protein into gastric epithelial cells. PLoS Pathog. 2009, 5 , e1000603.

49. Crabtree, J.E.; Ferrero, R.; Kusters, H. The mouse colonising Helicobacter pylori strain SS1 may lack a functional cag pathogenicity island. Helicobacter 2002, 7, 139-140.

50. Fu, S.; Ramanujam, K.S.; Wong, A.; Fantry, G.T.; Drachenberg, C.B.; James, S.P.; Meltzer, S.J.; Wilson, K.T. Increased expression and cellular localization of inducible nitric oxide synthase and cyloxygenase 2 in Helicobacter pylori gastritis. Gastroenterology 1999, 116, 1319-1329.

51. Caputo, R.; Tuccillo, C.; Manzo, B.A.; Zarrilli, R.; Tortora, G.; Blanco, C.V.; Ricci, V.; Ciardiello, F.; Romano, M. Helicobacter pylori VacA toxin up-regulates vascular endothelial growth factor expression in MKN 28 gastric epithelial cells through an epidermal growth factor receptor-, cycclooxygenase-2 dependent mechanism. Clin. Cancer Res. 2003, 9, 2015-2021.

52. Sierra, J.C.; Hobbs, S.; Chaturvedi, R.; Yan, F.; Wilson, K.T.; Peek, R.M., Jr.; Polk, B.R. Induction of COX-2 expression by Helicobacter pylori is mediated by activation of epidermal growth factor receptor in gastric epithelial cells. Am. J. Physiol. 2013, 305, G196-G203.

53. Wu, C.Y.; Wu, M.S.; Kuo, K.N.; Wang, C.B.; Chen, Y.J.; Lin, J.T. Effective reduction of gastric cancer risk with regular use of nonsteroidal anti-inflammatory drugs in Helicobacter pylori-infected patients. J. Clin. Oncol. 2010, 28, 2952-2957.

54. Tomtitchong, P. Host Epithelial Cell Signaling in Gastric Helicobacter pylori Infection. Ph.D. Thesis, University of Leeds, Leeds, UK, 2008.

55. Zanella, C.L.; Posada, P.; Tritton, T.R.; Mossman, B.T. Asbestos causes stimulation of the extracellular signal-regulated kinase 1 mitogen-activated protein kinase cascade after phosphorylation of the epidermal growth factor receptor. Cancer Res. 1996, 56, 5334-5338. 
56. Manning, C.B.; Cummins, A.B.; Jung, M.W.; Berlanger, I.; Timblin, C.R.; Palmer, C.; Taatjes, D.J.; Hemenway, D.; Vacek, P.; Mossman, B.T. A mutant epidermal growth factor receptor targeted to lung epithelium inhibits asbestos-induced proliferation and proto-oncogene expression. Cancer Res. 2002, 62, 4169-4175.

57. Roth, R.A.; Kapadia, S.B.; Martin, S.M.; Lorenz, R.G. Cellular immune responses are essential for development of Helicobacter felis associated gastric pathology. J. Immunol. 1999, 163, 1490-1497.

58. Shibita, W.; Hirata, Y.; Maeda, S.; Oguru, K.; Yania, A.; Mitsuno, Y.; Yamaji, Y.; Okamoto, M.; Yoshida, H.; Kawabe, T.; et al. CagA protein secreted by the intact type IV secretion system leads to gastric epithelial inflammation in the Mongolian gerbil model. J. Pathol. 2006, 210, 306-314.

59. Grimminger, F.; Schermuly, R.T.; Ghofrani, H.A. Targeting non-malignant disorders with tyrosine kinase inhibitors. Nat. Rev. Drug Discov. 2010, 9, 956-970.

(C) 2013 by the authors; licensee MDPI, Basel, Switzerland. This article is an open access article distributed under the terms and conditions of the Creative Commons Attribution license (http://creativecommons.org/licenses/by/3.0/). 